\title{
THE BENEFICIAL EFFECTS OF TONSILLAR FOSSA CLOSURE AFTER TONSILLECTOMY; A PROSPECTIVE STUDY
}

\author{
Muhanned M Al-Ali^, Ahmed M Al-Abbasi”, Haider Sabri Hashim*, \\ Haider K Saeed $^{\circledR}$, \& Ali M Altaie \\ ${ }^{\wedge} \mathrm{MB}, \mathrm{ChB}$, FIBMS, Department of Otolaryngology, Basrah Teaching Hospital. "FRCS, FIBMS, \\ Department of Surgery, Basrah College of Medicine. FIBMS, Department of Otolaryngology, Basrah \\ Teaching Hospital. ${ }^{\circledR}$ FIBMS, Department of Surgery, Medina General Hospital. "FIBMS, Abualkhaseeb \\ General Hospital, Basrah, IRAQ.
}

\begin{abstract}
The objective of this study is to evaluate the effect of tonsillar fossa closure after tonsillectomy on the amount of intra-operative blood loss, post-operative pain and bleeding.

Sixty patients enrolled in this single blind case control study held at Basrah Teaching Hospital in the period from July 2017 to November 2018. Patients age was between 7 to 50 years, of them $28(46.7 \%)$ females and $32(53.3 \%)$ males. One of tonsillar fossae was selected for closure and the other was left open as a control side, the duration of dissection, the amount of bleeding for each side, the level of post-operative pain on $(0$, $3,7,10-14$ ) days was estimated utilizing Visual Analogue Score (VAS) together with any evidence of post-operative bleeding.

There was statistically significant reduction in the level of post-operative pain in the sutured side compared to the control for all the follow-up periods. No significant differences in the amount of intra-operative blood loss between both sides were found. None of the patients experienced post-operative primary or secondary hemorrhage.

In conclusion, Closure of tonsillar fossa has beneficial effect in reducing the level of post-operative pain after tonsillectomy with no effect on post-operative bleeding. No difference was noted regarding the amount of intra-operative bleeding.

Keywords: Surgery, Tonsillectomy, Fossa closure, Bleeding, Pain
\end{abstract}

\section{Introduction}

$\mathrm{T}$ onsillectomy operation with or without adenoidectomy is by far the most commonly performed otolaryngological operation worldwide, but this operation is not without post-operative morbidity mainly in form of pain and bleeding together with possible nausea and vomiting ${ }^{1,2}$. After removing the tonsil out of it's fossa, a raw bed would be left behind, this bed contains the traumatized muscle fibers and the exposed nerve fibers of glossopharyngeal nerve. Because the healing of the fossae will be by secondary intention, so there will be a time for the bed to exposes to external environment that in turn will cause edema and spasm of the underlying muscle with considerable pain post-operatively. Thus, in turn, triggers an inflammatory process with subsequent release of cytokines in tonsillar bed that contributes to intense pain post-operatively ${ }^{3}$.

Many procedures advocated and many literature works have been made to overcome this particular problem (postoperative pain and bleeding) ${ }^{4-12}$.

The present study tries to learn the effect of protecting the fossae from irritation by the external environment, decreasing the 
nerve irritation, decreasing the edema and spasm of muscle fibers by closing the tonsillar fossa and isolating it from the exterior through suturing the pillars together.

\section{Patients and methods}

This prospective single blind casecontrol study was carried out in Otolaryngology Department at Basrah Teaching Hospital in the period between July-2017 to November-2018.

The primary number of patients who were included in this study and admitted for elective tonsillectomy was 77 .

Patients admitted for adenotonsillectomy were not included in this study to overcome the cumulative effect of pain caused by adenoidectomy and to avoid the extra amount of blood loss coming from the adenoid during dissection. A total of 17 patients (6 females and 11 males) were excluded for bleeding profile abnormalities, cardio- pulmonary compromise, diabetes, suspicion of malignancy and concurrent steroid intake. The remaining 60 patients represented the final sample size that was enrolled in this study. Each patient was followed-up for 14 days after operation.

The patients were interviewed for their sociodemographic information and their medical history. Detailed history, clinical and Otolaryngological examination was done for every patient enrolled in the study focusing on throat according to a pre-designed questioner.

Before the beginning of the operation, the suction jar was empty and the gauze of fixed size was weighted by digital scale to insure fixed size and weight and known amount of saline put in kidney dish which is the only amount utilized in cleaning the suction tip and at the end of the operation the remaining of the saline was sucked into the suction jar. The calculation of intraoperative blood loss was done using the following formula shown in box 1 .

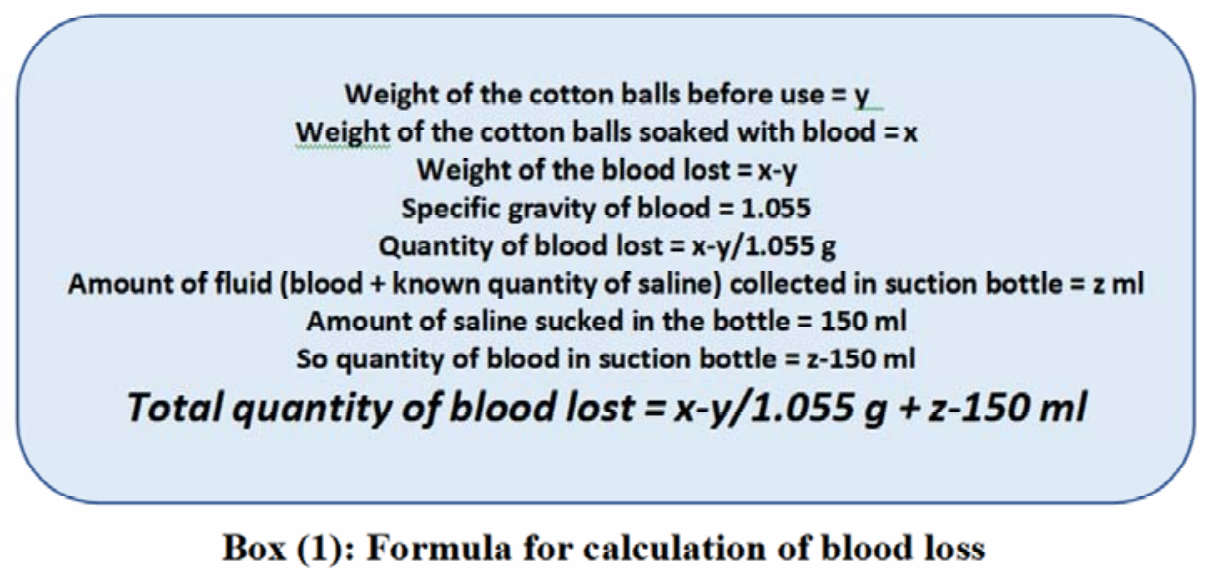

After removal of the tonsils and dealing with the prominent bleeding vessel by ligation, the fossa was packed with a piece of gel foam cut to fit the fossa for the purpose of hemostasis and filling the dead space that is created after removing of tonsillar tissue. Closure of tonsillar bed on one side was done by suturing the mucosa over the posterior pillar to that of anterior pillar with 3 interrupted sutures of $3 / 0$ or $4 / 0$ vicryl sutures leaving the contralateral tonsillar bed opened, ensuring no more bleeding exist and the pharynx and postnasal space was cleaned from any blood. The time taken for dissection and suturing was calculated by a valid timer. The level of pain was assessed by visual analogue score (VAS) which is shown in figure 1.

Visual analogue score interpreted as Mild (0-2), Moderate (3-7) and Severe (8-10), on day $0,3,7,10-14$ post-closure. 


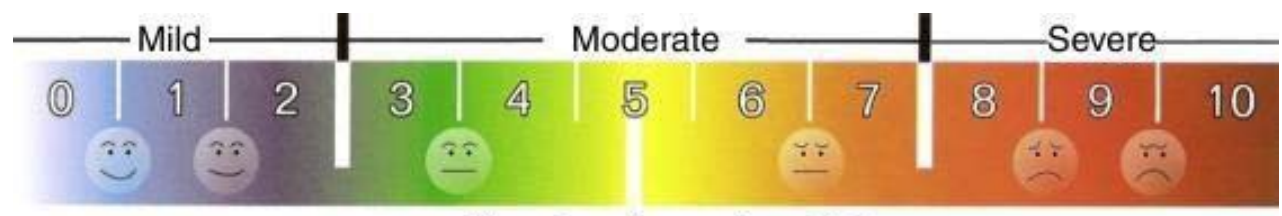

Visual analog scale - VAS

A colleague with good knowledge in using VAS helps in assessing the pain to avoid bias provided that he (the examiner) and the patient don't know which side is being closed. Assessment was done for the ability to resume feeding, feeling of foreign body sensation in their throat, otalgia, spitting of blood or frank blood, halitosis. The status of the sutures was assessed if they are slipped or not by examining the throat.

Data were analyzed using the IBM ${ }^{\circledR}$ SPSS ${ }^{\circledR}$ software version 23 and calculations were done utilizing (t-test) and (chi-square) for the purpose of comparing the two groups of the same sample before and after intervention,. A p-value of $<0.05$ was considered as significant.

\section{Results}

Of the 60 patients enrolled in this study, $28(46.7 \%)$ were females and 32 (53.3\%) were males. The age of the patients ranged from 7 to 50 years with a mean of 21.78 years. Dissection time was compared between the control and tested side which showed that it ranged from 519 minutes with an average of 9.8 minutes for the tested side, while it takes about 3-9 minutes with an average of 4.8 minutes for the control sides due to the added time of closing the pillar with sutures.

Intraoperative blood loss in the control side ranged from 1.3 to $62 \mathrm{ml}$ with a mean of $7.9 \mathrm{ml}$, while for the tested closed side it ranged from 1.3 to $55 \mathrm{ml}$ with a mean of $7.01 \mathrm{ml}$. There was no significant difference in the amount of blood loss between the two sides as the Pvalue was 0.55 .

Postoperative pain was also compared between the 2 sides in days $0,3,7$ and 10-14 postoperatively as shown in both table I and figure 2.

Table I: Severity of postoperative pain

\begin{tabular}{|l|l|l|l|l|l|}
\hline Day & Severity & control & percent & test & Percent \\
\hline 0 & Mild & 8 & 13.3 & 30 & 50 \\
\cline { 2 - 6 } & Moderate & 36 & 60 & 29 & 48.3 \\
\cline { 2 - 6 } & Sever & 16 & 26.7 & 1 & 1.7 \\
\hline 3 & Mild & 14 & 23.3 & 47 & 78.3 \\
\cline { 2 - 7 } & Moderate & 43 & 71.7 & 13 & 21 \\
\cline { 2 - 7 } & Sever & 3 & 5 & 0 & 0 \\
\hline 7 & Mild & 20 & 33.3 & 58 & 96.7 \\
\cline { 2 - 7 } & Moderate & 40 & 66.7 & 2 & 3.3 \\
\cline { 2 - 6 } & Sever & 0 & 0 & 0 & 0 \\
\hline \multirow{3}{*}{$10-14$} & Mild & 51 & 85 & 59 & 98.3 \\
\cline { 2 - 7 } & Moderate & 9 & 15 & 1 & 1.7 \\
\cline { 2 - 6 } & Sever & 0 & 0 & 0 & 0 \\
\hline
\end{tabular}

For the closed side only $1.7 \%$ had severe pain in day 0 postoperatively dropped to $0 \%$ on subsequent days, while in the control side $(26.7 \%)$ had severe pain in day 0 dropped to $5 \%$ in day 3 postoperatively and $0 \%$ in the following days. 

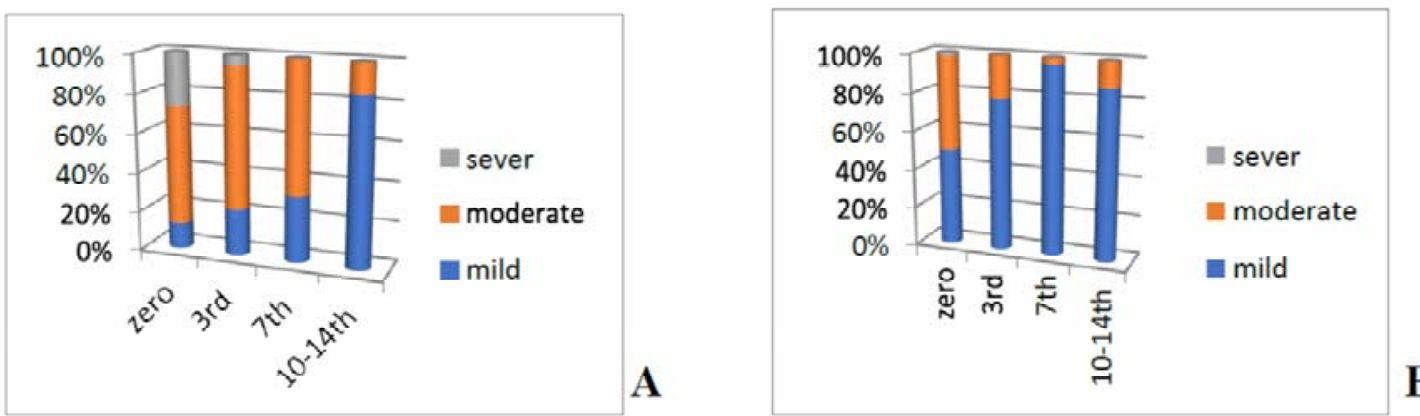

Figure 2: post-operative pain A: control side B: closed side

There was significant difference in the level of pain postoperatively between the control and tested side, P-value for day 0 was 0.000 , day 3 was 0.000 , day 7 was 0.000 and days $10-14$ was 0.001 .

There was a significant difference in the level of pain postoperatively between the control and tested side, P-value for day 0 was 0.000 , day 3 was 0.000 , day 7 was 0.000 and days $10-14$ was 0.001 .

The selection of side to be sutured was done randomly, 37 patients $(61.7 \%)$ on the right side while only 23 patients $(38.3 \%)$ had it on the left side.

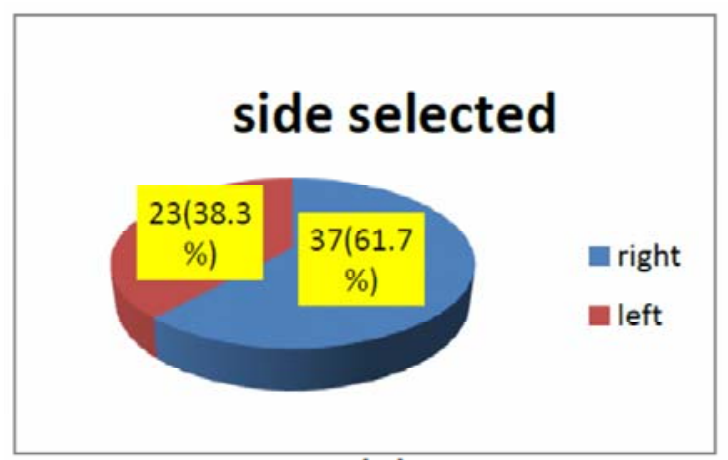

Figure (3)

None of the patients experienced primary or secondary hemorrhage, they didn't have foreign body sensation, and none of them had high grade fever. All of the patients resumed feeding normally but 3 patients experienced some swallowing difficulty ranging from 5-7 on VAS who were on the control side. Two of the patients experienced otalgia on day 0 which was resolved on the subsequent days, no palatal hematoma encountered but 2 patients experienced palatal edema on both sides which was resolved by day 3 .

\section{Discussion}

Pain, haemorrhage, edema, and infection are all a well known post tonsillectomy complications that usually occur in the early post-operative period $^{13-15}$. Post-tonsillectomy pain may be severe to cause significant patient discomfort and even dehydration due to refrain from eating especially children. Violation of soft tissue during tonsillar bed dissection will lead to release of inflammatory mediators like bradykinin, histamin, prostoglangins that stimulates the exposed nerve fiber causing pain in the throat together with post-operative edema at tonsillar fossae and spasm of pharyngeal muscle which comprises blood flow and exaggerating the postoperative pain ${ }^{15-17}$.

Closure of tonsillar fossa will convert healing process from secondary to primary intention which we suppose will have a beneficial effect on posttonsillectomy complications. In the present study, we include wide age 
groups ranging from 7 to 50 year, ages below 7 were excluded for the fear of bad cooperation and assessment. Nandapalan et al and Weighill et al evaluate only those ages above 15 years that narrowed the spectrum of evaluation ${ }^{13,14}$. Genç et al although include ages below 7 but he didn't include those above 15 years ${ }^{15}$.

Cold steel dissection and suture ligation is used during tonsillectomy as other modalities of dissection like electrodissection have a conflicting result in increasing postoperative pain and morbidity. While both Burce et al, Nandanpalan et al, Waxler et al and Silveria et al used elecrodissection during tonsillectomy ${ }^{13,18,19}$.

Results of our study showed that the severity of pain is much lower on the suture side as compared to the control side where about $50 \%, 78 \%$ and $98 \%$ of patient experienced mild pain in the day 0,3 and 10 of follow-up respectively in contrast to the non-sutured where moderate pain encountered in $60 \%, 71 \%$ and $15 \%$ of patients in days 0,3 and 10 of follow-up respectively. This difference is statistically significant where p-value was $<0.05$ all over the days of follow-up, day $0 \quad(\mathrm{p}=.000)$, day $3(\mathrm{p}=.000)$, day 7 $(\mathrm{p}=.000)$, day $10 \quad(\mathrm{p}=.001)$, the more severe pain was experienced in the first week post tonsillectomy which then decreases dramatically on 7 th to 10 th days as shown in table I and figure 1, this results was comparable to those of Sendi et al, Genç et al and Nandapalan et al who found no statically different pain level between the 2 sides on first day where Genç et al found the $\mathrm{p}$ value $>0.01$ and Nandapalan et al stated that more severe pain was experienced in sutured side by the first day only ${ }^{13,15,17}$.

Matt et al found that suturing the pillar increases the odd ratio of pain in the sutured side by $40 \%$ which contradict with the present study, the explanation for that probably because Bruce et al uses means that increases the pain score postoperatively for example electrocautery which in many studies is known to increases pain score postoperatively, also the patients enrolled did not have absolute tonsillectomy but it was combined with other issues like adenoidectomy which may cause more pain in addition to tonsillectomy.

The time needed for dissection was increased by about 6 minutes due to the added time of suturing that is comparable with Genç et al, those added minutes had no adverse effect in terms of anesthesia or patient tolerance ${ }^{15}$.

This study shows no significant difference in the amount of intraoperative blood loss which was similar to the results of other studies, Weighill et al, Nandanpalan et al,

Bruce etal, Ramjettan et al, Sendi et al and Genç et al, with maximum blood loss for the control side $(62 \mathrm{ml})$ and that for tested side $(55 \mathrm{ml})$, p-value was $0.55^{13-17}$. Post-tonsillectomy hemorrhage either primary or secondary did not occur during the follow- period, that is similar to Nandapalan et al, Sendi et al and Weighill et al, but Genç et al and Ramjettan et al had post-tonsillectomy bleeding in some of their patients on the unsutured side which was not statically significant ${ }^{13-17}$.

No palatal hematoma was detected in the present study during the follow-up period which is similar to the result of Nandapalan et al and Genç et al, while Weighill et al had 3 subjects with palatal hematoma and Ramjettan et al had 2 subjects, both of them uses catgut suture. The hematoma development may relate to the type of suture used, because catgut is known to cause more tissue reaction than other sutures which is an issue that need more investigations ${ }^{14-16}$.

Two of our patients developed mild edema of the palate after the operation which was resolved by the 3 rd day. This contradict to Genç et el who had statistically significant palatal edema on the sutured side although this edema did not increase pain experience as he stated, 
again Genç et al used catgut suture during closure which contributed for the edema but need more investigation ${ }^{15}$.

In many studies like Weighill et al, Genç et al, Nandanpalan et al, Sendi et al, Ramjettan et al and Bruce et al and the present study had no limitation for commencing early feeding, meaning that suture ligation has no effects on swallowing, except for the pain that patients experienced which is mainly on the unsutured side ${ }^{13-17}$.
In conclusion, the closure of tonsillar fossa, apart from the added few minutes in operation duration, is an effective way in reduction of post-tonsillectomy pain, which is adversely, affects patient's response to the procedure and subsequent development of emotional stress to the patient and family. It also reduces the fear of commencing eating and drinking, and improve early recovery.

\section{References}

1. Wiggins SA, Foster RL. Pain after tonsillectomy and adenoidectomy:"ouch it did hurt bad". Pain Management Nursing. 2007;8(4):156-65.

2. Sutters KA, Miaskowski C, Holdridge-Zeuner D, Waite S, Paul SM, Savedra MC, et al. Timecontingent dosing of an opioid analgesic after tonsillectomy does not increase moderate-to- severe side effects in children. Pain Management Nursing. 2005;6(2):49-57.

3. Magdalena M, Solé A, Blanco V, Rodrigo J. Histological analysis of tonsillectomies: relationship with surgical technique, post-operative pain and haemorrhage. The Journal of Laryngology \& Otology. 2016;130(12):1142-6.

4. Kharodawala M, Ryan M. The modern tonsillectomy. Grand Rounds Presentation. 2005:1- 60 .

5. Gupta A, Gupta S, Meena DS, Sharma U. Post-tonsillectomy pain: different modes of pain relief. Indian Journal of Otolaryngology and Head and neck surgery. 2002;54(2):136.

6. Elassy AE-HR, Mohamed AAE, Abo-Elnaga HAE, Saleh WM. Measures to Reduce Post Tonsillectomy Pain. American Journal of Clinical and Experimental Medicine. 2015;3(5):237- 40.

7. Elhakim M, Ali NM, Rashed I, Riad MK, Refat M. Dexamethasone reduces postoperative vomiting and pain after pediatric tonsillectomy. Canadian Journal of Anesthesia. 2003;50(4):392-7.

8. Topal K, Aktan B, Sakat MS, Kilic K, Gozeler MS. Post-operative pain control after tonsillectomy: dexamethasone vs tramadol. Acta oto-laryngologica. 2017;137(6):618-22.

9. Volk MS, Martin P, Brodsky L, Stanievich JF, Ballou M. The effects of preoperative steroids on tonsillectomy patients. Otolaryngology_Head and Neck Surgery. 1993;109(4):726- 30.

10. Attia TM. Effect of paracetamol/prednisolone versus paracetamol/ibuprofen on post- operative recovery after adult tonsillectomy. American journal of otolaryngology. 2018.

11. Acar B, Babademez MA, Karabulut H. Topical hemostatic agents in otolaryngologic surgery. Kulak Burun Bogaz Ihtis Derg. 2010;20(2):100-9.

12. Al-Abbasi AM, Saeed ZK. Hydrogen Peroxide 3\%: Is it Beneficial in Tonsillectomy? Sultan Qaboos University Medical Journal. 2008;8(2):201.

13. Nandapalan V, McIlwain J. Tonsillar fossa obliteration and post-operative pain. Clinical Otolaryngology \& Allied Sciences. 1995;20(2):127-9.

14. Weighill J, Proops D, Jeffries D, Brandrick J. Pain relief following tonsillectomy (Does sewing the faucial pillars to gether help?). The Journal of Laryngology \& Otology. 1986;100(3):307-10.

15. Genç E, Hancı D, Ergin NT, Dal T. Can mucosal sealing reduce tonsillectomy pain? International journal of pediatric otorhinolaryngology. 2006;70(4):725-30.

16. Ramjettan S, Singh B. Are sutured faucial pillars really an advantage in tonsillectomy? South African journal of surgery Suid-Afrikaanse tydskrif vir chirurgie. 1996;34(4):189-91.

17. Sendi KS, Zawawi FT, Al-Amry S, Alnoury I, Al-Radadi AM. Tonsillar fossa closure: a quest in tonsillectomy pain reduction. Medical Science. 2009;16(3).

18. Wexler DB. Recovery after tonsillectomy: electrodissection vs. sharp dissection techniques. Otolaryngology_Head and Neck Surgery. 1996;114(4):576-81.

19. Silveira H, Soares JS, Lima HA. Tonsillectomy: cold dissection versus bipolar electrodissection. International journal of pediatric otorhinolaryngology. 2003;67(4):345-51. 